\title{
High level of EZH2 expression is linked to high density of CD8-positive T-lymphocytes and an aggressive phenotype in renal cell carcinoma
}

\author{
Till Eichenauer ${ }^{1} \cdot$ Luca Simmendinger $^{1} \cdot$ Christoph Fraune $^{2} \cdot$ Tim Mandelkow $^{2} \cdot$ Niclas C. Blessin $^{2} \cdot$ Martina Kluth $^{2}$. \\ Claudia Hube-Magg ${ }^{2} \cdot$ Katharina Möller $^{2} \cdot$ Till Clauditz $^{2} \cdot$ Sören Weidemann ${ }^{2} \cdot$ Roland Dahlem $^{1} \cdot$ Margit Fisch $^{1}$. \\ Silke Riechardt ${ }^{1} \cdot$ Ronald Simon $^{2} \cdot$ Guido Sauter $^{2} \cdot$ Franziska Büscheck $^{2} \cdot$ Michael Rink $^{1}$
}

Received: 6 November 2019 / Accepted: 3 April 2020 / Published online: 17 April 2020

(c) The Author(s) 2020

\begin{abstract}
Purpose Enhancer of zeste homolog 2 (EZH2), the catalytic part of the Polycomb repressive complex 2 (PRC2), has a prognostic role in renal cell carcinoma (RCC) and was recently shown to modulate the immune response by reducing tumor cell immunogenicity.

Methods To investigate whether the prognostic role of EZH2 might be driven by a modified immune environment, more than 1800 RCCs were analyzed in a tissue microarray for EZH2 expression and CD8 positive lymphocytes were quantitated by automated digital imaging.

Results EZH2 positivity was found in $75.2 \%$ of 1603 interpretable tumors. In clear cell RCC, high EZH2 expression was significantly linked to high ISUP, Furmann, and Thoenes grade $(p<0.0001$ each), advanced stage $(p<0.0001)$, nodal $(p=0.0190)$ and distant metastasis $(p<0.0001)$ as well as shortened overall $(p<0.0027)$ and recurrence free survival $(p<0.0001)$. The density of CD8+ cells varied from 0 to 5048 cells $/ \mathrm{mm}^{2}$ (Median 120 cells $/ \mathrm{mm}^{2}$ ). A high CD8+ count was significantly associated with high ISUP, Fuhrmann, and Thoenes grade ( $p<0.0001$ each), advanced tumor stage $(p=0.0041)$, distant metastasis $(p=0.0026)$ as well as reduced overall survival $(p=0.0373)$ and recurrence free survival $(p=0.0450)$. The density of CD8+ cells continuously increased with raising EZH2 levels $(p<0.0001)$.

Conclusion Our data support a striking prognostic role of both EZH2 expression and the density of CD8+ cells in RCC. The tight relationship of EZH2 expression and CD8+ cell counts in RCC is consistent with models suggesting that EZH2 overexpression can be caused by high lymphocyte content in certain tumor types. Such a mechanism could explain the unique finding of high lymphocyte counts driving poor prognosis in RCC patients.
\end{abstract}

Keywords Renal cell carcinoma $\cdot$ CD8 $\cdot$ EZH2 $\cdot$ Tissue microarrays

\section{Introduction}

Renal cell carcinoma (RCC) is one of the most common tumors worldwide [1]. Localized tumors are generally treated surgically, whereas for advanced tumors necessitating systemic treatment, several new drugs were approved lately and have improved the still unfavorable prognosis of

Ronald Simon

r.simon@uke.de

1 Department of Urology, University Medical Center Hamburg-Eppendorf, Hamburg, Germany

2 Institute of Pathology, University Medical Center Hamburg-Eppendorf, Martinistraße 52, 20246 Hamburg, Germany metastatic disease [2, 3]. As in other cancer types, immunecheckpoint inhibitors are in focus of current kidney cancer research [4-6]. In clear cell RCC, a combination of the Ipilimumab (CTLA-4 inhibitor) and nivolumab (PD-1 inhibitor), pembrolizumab (PD-1 inhibitor) and axitinib (VEGFR inhibitor), and avelumab (PD-L1 inhibitor) and axitinib (VEGFR inhibitor) showed superior survival in a phase III study and is now recommended as first line systemic therapy in intermediate- and poor-risk patients [2, 7-9].

Current clinical trials evaluate whether adjuvant application of immune-checkpoint inhibitors or other new drugs can improve the prognosis of patients with kidney cancer in high risk situations, such as tumor recurrence or progression after nephrectomy (Keynote-564, IMmotion010, Checkmate-914). If adjuvant treatment becomes standard 
of care, risk stratification will become more important than ever before, to find out which patient is at risk and might benefit from extended treatment. A better understanding of disease biology will potentially lead to the identification of clinically applicable molecular markers that enable a more reliable prediction of kidney cancer aggressiveness.

Enhancer of zeste homolog 2 (EZH2) is of potential interest in kidney cancer. EZH2 is the catalytic part of the Polycomb repressive complex 2 (PRC2) [10]. Through trimethylation of Histone 3 on lysine 27 (H3K27me3) it induces chromatin compaction and transcriptional repression of various genes including p16 and E-Cadherin [11, 12]. EZH2 also interacts with various non-histone proteins and can serve as a transcriptional activator [13]. Studies have suggested that high levels of EZH2 expression in cancer tissue may be strongly linked to poor patient prognosis. This includes several studies on kidney cancer [14-22]. Importantly, EZH2 has recently been shown to modulate the immune response to tumor cells by reducing their immunogenicity [23].

To investigate whether the prognostic role of EZH2 might be driven by a modified immune response, a cohort of 1809 renal cell carcinomas was analyzed in a tissue microarray format (TMA) for EZH2 protein expression and CD8+ lymphocytes were quantitated by automated digital imaging.

\section{Materials and methods}

\section{Patients}

A set of kidney tumor tissue microarrays (TMAs) was used containing one tissue core each from 1809 kidney tumors routinely diagnosed from nephrectomy specimen between 1994 and 2016 at the Institute of Pathology of the University Medical Center Hamburg-Eppendorf, Germany. All tumors had been reviewed according to the criteria described in the 2016 WHO classification by two pathologists with a special focus on genitourinary pathology $(\mathrm{FB}, \mathrm{CF})$ and ISUP (International Society of Urologic Pathologists) grading was performed for each tumor. Follow-up data were available for 777 of 1176 clear cell cancers. Available study endpoint were overall survival and recurrence free survival, including patients without metastasis (M0) at the timepoint of surgery and patients with initial metastasis (M1) and additional progress after surgery. The TMA comprises four blocks, one of which had been earlier used [24]. The TMA manufacturing process was described in detail before [25]. In brief, from each donor tumor, one tissue core measuring $0.6 \mathrm{~mm}$ in diameter was taken from a tumor-containing tissue block. Clinical and pathological parameters of the arrayed tumors are summarized in Table 1. The mean follow-up time was 48 months.
Table 1 Clinico-pathological features of 1809 arrayed renal cell cancers

\begin{tabular}{|c|c|}
\hline & $\begin{array}{l}\text { Study } \\
\text { cohort on } \\
\text { TMA } \\
(n=1809)\end{array}$ \\
\hline \multicolumn{2}{|l|}{ Follow-up } \\
\hline Available $(n)$ & 1174 \\
\hline Mean (months) & 48 \\
\hline Median (months) & 61.8 \\
\hline \multicolumn{2}{|l|}{ Age (years) } \\
\hline$<50$ & 263 \\
\hline $50-70$ & 951 \\
\hline $70-90$ & 595 \\
\hline \multicolumn{2}{|l|}{ Histology } \\
\hline Clear cell RCC & 1167 \\
\hline Papillary RCC & 270 \\
\hline Chromophobe RCC & 101 \\
\hline Oncocytoma & 149 \\
\hline \multicolumn{2}{|l|}{ UICC stage } \\
\hline I & 733 \\
\hline II & 131 \\
\hline III & 175 \\
\hline IV & 158 \\
\hline \multicolumn{2}{|l|}{ pT category } \\
\hline pT1 & 998 \\
\hline pT2 & 223 \\
\hline pT3-4 & 408 \\
\hline \multicolumn{2}{|l|}{ ISUP grade } \\
\hline 1 & 398 \\
\hline 2 & 537 \\
\hline 3 & 469 \\
\hline 4 & 100 \\
\hline \multicolumn{2}{|l|}{ Fuhrman grade } \\
\hline 1 & 72 \\
\hline 2 & 851 \\
\hline 3 & 480 \\
\hline 4 & 110 \\
\hline \multicolumn{2}{|l|}{ Thoenes grade } \\
\hline 1 & 497 \\
\hline 2 & 839 \\
\hline 3 & 177 \\
\hline \multicolumn{2}{|l|}{ pN category } \\
\hline pNO & 232 \\
\hline $\mathrm{PN}+$ & 49 \\
\hline \multicolumn{2}{|l|}{ pM category } \\
\hline pM0 & 220 \\
\hline $\mathrm{pM}+$ & 148 \\
\hline
\end{tabular}

Numbers do not always add up to 1809 in the different categories because of missing data 


\section{Immunohistochemistry (IHC)}

Freshly cut TMA sections were immunostained on 1 day and in one experiment. Slides were deparaffinized and exposed to heat-induced antigen retrieval for $5 \mathrm{~min}$ in an autoclave at $121{ }^{\circ} \mathrm{C}$ at $\mathrm{pH} 9(\mathrm{EZH} 2)$ or $\mathrm{pH} 7.8$ (CD8) Tris-EDTA-Citrate buffer. Primary antibody specific for EZH2 (mouse monoclonal antibody, Abnova, Taipeh, Taiwan; cat\#MAB9542; dilution 1:150) was applied at $37{ }^{\circ} \mathrm{C}$ for $60 \mathrm{~min}$. Bound antibody was then visualized using the EnVision Kit (Dako, Glostrup, Denmark) according to the manufacturer's directions. EZH2 staining was predominantly nuclear and no staining was found in normal tissue. EZH2 staining was typically found in either all $(100 \%)$ or none $(0 \%)$ of the tumor cells in a given cancer spot. Staining intensity of all cases was thus semi-quantitatively assessed in four categories: negative, weak, moderate and strong. The percentage of positive tumor cells (typically 100\%) was not separately recorded. For CD8 staining, the slides were deparaffinized, rehydrated, exposed to heat-induced antigen retrieval for $15 \mathrm{~min}$ at $98{ }^{\circ} \mathrm{C}$ in pH9 DAKO target retrieval Solution (S2367) using a DAKO PT-LINK device and then transferred to a DAKO Link 48 autostainer device. The autostainer protocol includes peroxidase blocking for 5 min (DAKO, Envision Flex-Kit 8002) and subsequent incubations of the primary antibody (Oncodianova, mouse monoclonal antibody, Clone TC8, dilution 1:200) for $20 \mathrm{~min}$ at room temperature, Flex HRP (DAKO EnVision Flex-Kit 8002) for $20 \mathrm{~min}$, DAB-Chromogen (DAKO EnVision Fley-Kit 8002) for $10 \mathrm{~min}$ as well as a final incubation with Hämatoxylin (DAKO K8008) for 5 min.

\section{Quantification of CD8 immunostaining}

Digital images of CD8-stained slides were acquired using Leica's Aperio VERSA 8 automated microscope. TMA spots were automatically identified and analyzed using Image Scope 12.3.3 software package (Leica Microsystems, Wetzlar, Germany) according to the following procedure: Every TMA slide was scanned at $40 \times$ magnification. Digital images were segmented using the Image Scope TMA-Tool and the segmentation was corrected manually. Two Aperio ePathology Image Analysis macros were adjusted (Leica Microsystems, Wetzlar, Germany) to determine the number of CD8+ cells in each tissue spot and to measure the corresponding exact area of each tissue spot. The number of stained cells and the area in square millimeters of each individual spot was used to calculate the density of stained cells/ $\mathrm{mm}^{2}$ (number of cells per square $\mathrm{mm}$ ). Threshold selection was done according to Galon et al. [26]. In brief, the cutoff providing the highest survival difference was selected. In our study, this cutoff was 142 cells $/ \mathrm{mm}^{2}$ to separate "low" from "high" CD8 density.

\section{Statistics}

Statistical calculations were performed with JPM 14 software (SAS Institute Inc, NC, USA). Contingency tables and the Chi-square test were performed to search for associations between EZH2 or CD8 and tumor phenotype as well as tumor subtype. Survival curves were calculated according to Kaplan-Meier. The log-rank test was applied to detect significant survival differences between groups analysis of variance (ANOVA) tests were used to investigate the relationship between categorical and continuous data.

\section{Technical issues}

1603 of $1809(88.6 \%)$ tissue spots were informative for EZH2. Reasons for non-informative TMA spots were lack of tissue spots in the TMA section or lack of sufficient amounts of tumor cells in a TMA spot. For CD8, only an "unusual" low number of tissue spots (1163 of 1809, 64.3\%) were interpretable, because tumors spots lacking detectable CD8+ lymphocytes were excluded from further analysis. Accordingly, analysis of both markers (CD8 and EZH2) was successful in 1,075 of $1,809(59.4 \%)$ of the arrayed cancers.

\section{Results}

\section{EZH2 expression in renal cell cancer}

In normal kidney tissue EZH2 staining was not observed, but in a fraction of cancers, nuclear EZH2 immunostaining was present, however. Representative images of EZH2 positive and negative cancers are given in Fig. 1. In total, EZH2 positivity was found in $75.2 \%$ of 1603 analyzable cancers, including $63.1 \%$ tumors with weak, $8.0 \%$ with moderate, and $4.1 \%$ with strong immunostaining according to our criteria. EZH2 expression varied slightly between the different histological subtypes (Table 2). EZH2 expression was most commonly seen in papillary cancers $(87.0 \%$ positive) and least frequent in oncocytomas $(63.1 \%)$ and chromophobe cancers (64.1\%; Table 2). The search for associations between EZH2 expression and tumor phenotype was limited to the largest subset of 1053 analyzable clear cell RCC (Table 3). The number of samples was too small for a statistically meaningful analysis in papillary, chromophobe and other cancer types. In clear cell RCC, high (moderate to strong) EZH2 expression was significantly linked to high ISUP, Fuhrmann, and Thoenes grade ( $p<0.0001$ each), advanced stage $(p<0.0001)$, nodal metastasis $(p=0.0190)$, and distant metastasis $(p<0.0001)$. Follow-up data were available for 698 (overall survival) or 649 (recurrence free survival) clear cell cancers with analyzable EZH2 immunostaining. The validity of the follow-up data is demonstrated in Fig. 2a, b, 
Fig. 1 EZH2 immunostaining in clear cell renal cell carcinomas. a Negative staining, b weak staining, c moderate staining, and $\mathbf{d}$ strong staining

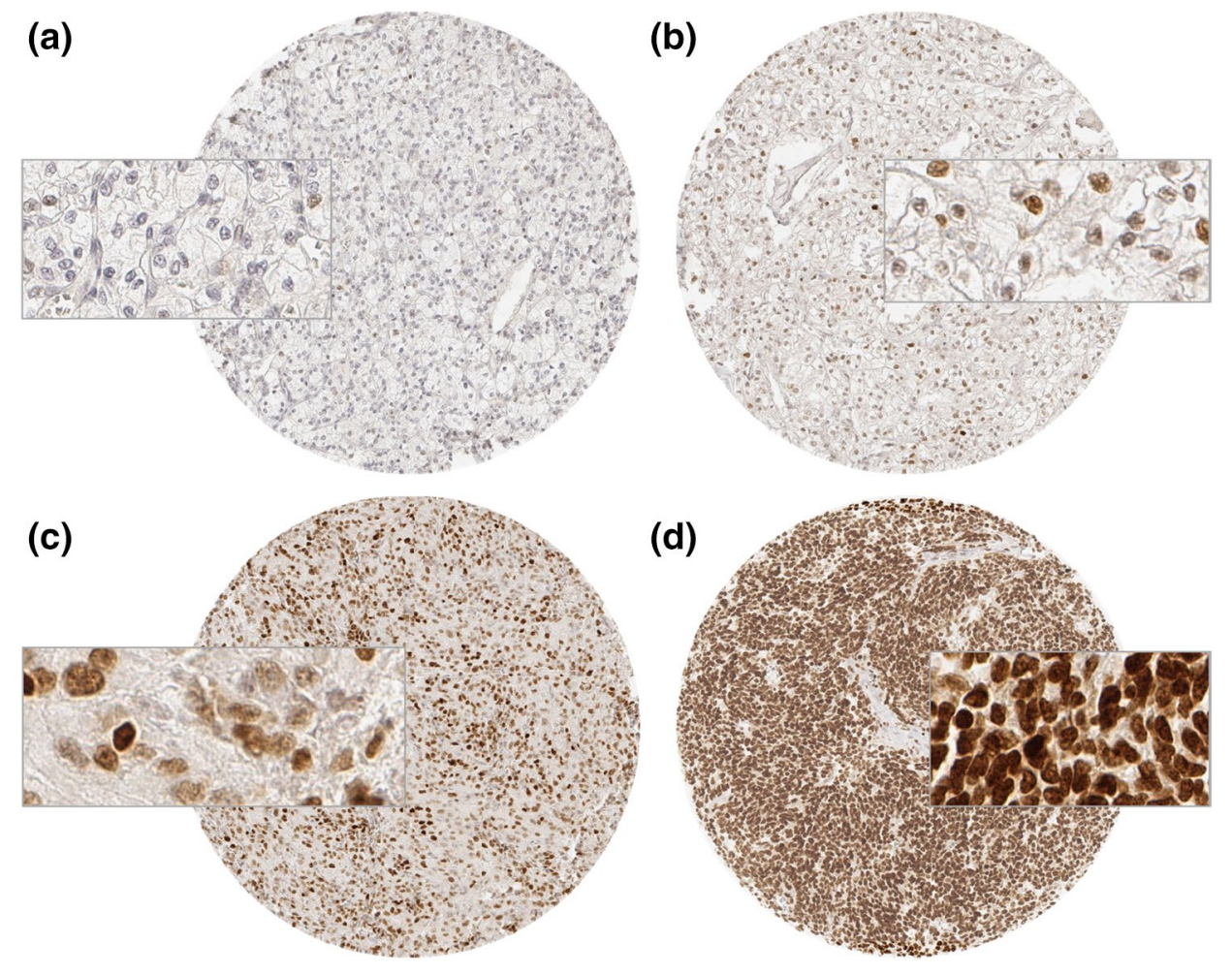

Table 2 Comparison between EZH2 immunostaining and renal cell cancer subtypes

\begin{tabular}{|c|c|c|c|c|c|}
\hline \multirow[t]{2}{*}{ Entity } & \multirow[t]{2}{*}{ Analyzable $(n)$} & \multicolumn{4}{|l|}{$\mathrm{EZH} 2$} \\
\hline & & Negative (\%) & Weak $(\%)$ & Moderate $(\%)$ & Strong $(\%)$ \\
\hline Renal cell cancers (RCC) & 1603 & $397(24.8 \%)$ & $1012(63.1 \%)$ & $128(8 \%)$ & $66(4.1 \%)$ \\
\hline Clear cell RCC & 1053 & $266(25.2 \%)$ & $691(65.6 \%)$ & $63(6 \%)$ & $34(3.2 \%)$ \\
\hline Papillary RCC & 238 & $31(13 \%)$ & $144(60.5 \%)$ & $49(20.6 \%)$ & $14(5.9 \%)$ \\
\hline Chromophobe RCC & 92 & $33(35.9 \%)$ & $54(58.7 \%)$ & $4(4.3 \%)$ & $1(1.1 \%)$ \\
\hline Clear cell tubulopapillary RCC & 28 & $7(25 \%)$ & $19(67.9 \%)$ & $2(7.1 \%)$ & $0(0 \%)$ \\
\hline Oncocytomas & 122 & $45(36.9 \%)$ & $74(60.7 \%)$ & $2(1.6 \%)$ & $1(0.8 \%)$ \\
\hline Other rare types & 69 & $15(21.7 \%)$ & $30(43.5 \%)$ & $8(11.6 \%)$ & $16(23.2 \%)$ \\
\hline
\end{tabular}

where significant associations between tumor stage or Fuhrman grade with overall survival are shown in the subset of clear cell cancers. There was a statistically significant association between high EZH2 expression and reduced overall survival ( $p=0.0027$, Fig. 2c) and recurrence free survival in the subset of clear cell RCC ( $p<0.0001$, Fig. $2 d)$.

\section{Density of CD8+ T-lymphocytes in renal cell carcinoma}

The count of CD8+ cells differed widely from 0 to 5048 cells $/ \mathrm{mm}^{2}$ in 1163 interpretable cancers (Median 120; mean 342 cells $/ \mathrm{mm}^{2}$ ). The density of CD8+ cells differed markedly between different tumor entities (Table 4) and was lowest in oncocytomas (mean 47.2) and highest in clear cell carcinomas (430.4). The comparison of the density of CD8+ cells with tumor phenotype and outcome was again limited to 770 clear cell RCC. A high density of CD8+ cells was significantly associated with high ISUP, Fuhrmann, and Thoenes grade $(p<0.0001$ each) and distant metastasis $(p=0.0026$, Table 5). High numbers of CD8, defined as $\geq 142$ cells $/ \mathrm{mm}^{2}$, were also linked with reduced overall survival $(p=0.0373)$ and recurrence free survival $(p=0.0450$, Fig. 2e, f).

\section{Multivariate analyses}

In clear cell cancers, multivariate analyses including the established prognosticators pT, pN, pM and Fuhrmann grade in addition to either EZH2 immunostaining or CD8+ cell 
Table 3 Comparison of EZH2 immunostaining and clinicopathological features in clear cell

\begin{tabular}{|c|c|c|c|c|c|c|}
\hline Parameter & Analyzable $(n)$ & Negative (\%) & Weak (\%) & Moderate $(\%)$ & Strong $(\%)$ & $p$ value \\
\hline \multicolumn{7}{|l|}{ ISUP } \\
\hline 1 & 275 & $86(31.3 \%)$ & $182(66.2 \%)$ & $5(1.8 \%)$ & $2(0.7 \%)$ & \multirow[t]{4}{*}{$<0.0001$} \\
\hline 2 & 353 & $106(30 \%)$ & $232(65.7 \%)$ & $12(3.4 \%)$ & $3(0.9 \%)$ & \\
\hline 3 & 338 & $60(17.8 \%)$ & $234(69.2 \%)$ & $29(8.6 \%)$ & $15(4.4 \%)$ & \\
\hline 4 & 78 & $13(16.7 \%)$ & $35(44.9 \%)$ & $16(20.5 \%)$ & $14(18 \%)$ & \\
\hline \multicolumn{7}{|l|}{ Fuhrmann } \\
\hline 1 & 42 & $15(35.7 \%)$ & $27(64.3 \%)$ & $0(0 \%)$ & $0(0 \%)$ & \multirow[t]{4}{*}{$<0.0001$} \\
\hline 2 & 574 & $173(30.1 \%)$ & $381(66.4 \%)$ & $15(2.6 \%)$ & $5(0.9 \%)$ & \\
\hline 3 & 348 & $62(17.8 \%)$ & $239(68.7 \%)$ & $34(9.8 \%)$ & $13(3.7 \%)$ & \\
\hline 4 & 89 & $16(18 \%)$ & $43(48.3 \%)$ & $14(15.7 \%)$ & $16(18 \%)$ & \\
\hline \multicolumn{7}{|l|}{ Thoenes } \\
\hline 1 & 342 & $106(31 \%)$ & $222(64.9 \%)$ & $11(3.2 \%)$ & $3(0.9 \%)$ & \multirow[t]{3}{*}{$<0.0001$} \\
\hline 2 & 572 & $137(24 \%)$ & $390(68.2 \%)$ & $32(5.6 \%)$ & $13(2.3 \%)$ & \\
\hline 3 & 139 & $23(16.6 \%)$ & $78(56.1 \%)$ & $20(14.4 \%)$ & $18(13 \%)$ & \\
\hline \multicolumn{7}{|c|}{ Tumor stage } \\
\hline pT1 & 593 & $145(24.5 \%)$ & $415(70 \%)$ & $25(4.2 \%)$ & $8(1.4 \%)$ & \multirow[t]{4}{*}{$<0.0001$} \\
\hline pT2 & 134 & $38(28.4 \%)$ & $85(63.4 \%)$ & $7(5.2 \%)$ & $4(3 \%)$ & \\
\hline pT3 & 307 & $79(25.7 \%)$ & $182(59.3 \%)$ & $27(8.8 \%)$ & $19(6.2 \%)$ & \\
\hline pT4 & 13 & $2(15.4 \%)$ & $4(30.8 \%)$ & $4(30.8 \%)$ & $3(23.1 \%)$ & \\
\hline \multicolumn{7}{|c|}{ Lymph node metastasis } \\
\hline pNO & 164 & $37(22.6 \%)$ & $113(68.9 \%)$ & $10(6.1 \%)$ & $4(2.4 \%)$ & \multirow[t]{3}{*}{0.019} \\
\hline $\mathrm{pN} 1$ & 10 & $1(10 \%)$ & $6(60 \%)$ & $1(10 \%)$ & $2(20 \%)$ & \\
\hline $\mathrm{pN} 2$ & 22 & $3(13.6 \%)$ & $11(50 \%)$ & $6(27.3 \%)$ & $2(9.1 \%)$ & \\
\hline \multicolumn{7}{|c|}{ Distant metastasis } \\
\hline pM0 & 138 & $31(22.5 \%)$ & $102(73.9 \%)$ & $5(3.6 \%)$ & $0(0 \%)$ & \multirow[t]{2}{*}{$<0.0001$} \\
\hline pM1 & 119 & $30(25.2 \%)$ & $64(53.8 \%)$ & $12(10.1 \%)$ & $13(10.9 \%)$ & \\
\hline
\end{tabular}

Numbers do not always add up to 1053 in the different categories because of missing data renal cell cancers counts showed that neither EZH2 nor the density of CD8+ cells were independent prognosticators (overall survival: $p=0.2970$ for $\mathrm{EZH} 2$ and $p=0.1179$ for $\mathrm{CD} 8$; recurrence free survival $p=0.3890$ for $\mathrm{EZH} 2$ and $p=0.6002$ for $\mathrm{CD} 8$ ).

\section{EZH2 expression and CD8 cell count}

Data on both EZH2 and CD8 immunohistochemistry was available for 1075 cancers. The comparison between EZH2 expression and CD8+ cell counts revealed that the number of CD8+ cells continuously increased with raising $\mathrm{EZH} 2$ levels. This held true for the group of all cancers $(p<0.0001)$ as well as for the subgroup of clear cell RCC (Fig. 3, $p<0.0001$ ).

\section{Discussion}

In this study EZH2 immunostaining was seen in $75.2 \%$ of kidney cancers. This is in the middle of the range reported in earlier studies. Using immunohistochemistry, EZH2 protein was detected in $44 \%$ of 110 [22], $78 \%$ of 165 [17], 84\% of
119 [27], $89 \%$ of 520 [16], $100 \%$ of 257 [28], $100 \%$ of 185 [19], and $100 \%$ of 50 [29] kidney cancers. Differences in the EZH2 levels between these studies are likely to be caused by differences between antibodies selected, protocols used for immunostaining, and/or criteria for interpretation. Given the relatively mild differences between different kidney cancer subgroups observed in our study, it appears unlikely that the composition of RCC subtypes was a major contributing factor.

We do not consider it as a limitation that a TMA with only one $0.6 \mathrm{~mm}$ tissue core per tumor was analyzed in our study. Early studies have demonstrated, that all known associations between molecular features and cancer phenotype could be reproduced in TMAs. For example, Kononen et al. found the same frequencies of HER2, cMYC and Cyclin D1 in breast cancer as were expected in previous large sections studies [25]. Nocito et al. determined the Ki67LI on four replicated TMAs and associated large sections and found the same associations between Ki67LI and tumor phenotype and prognosis in both applications in bladder cancer [30]. Although it is possible that some positive EZH2 cancers were not detected because of potential genetic heterogeneity, 

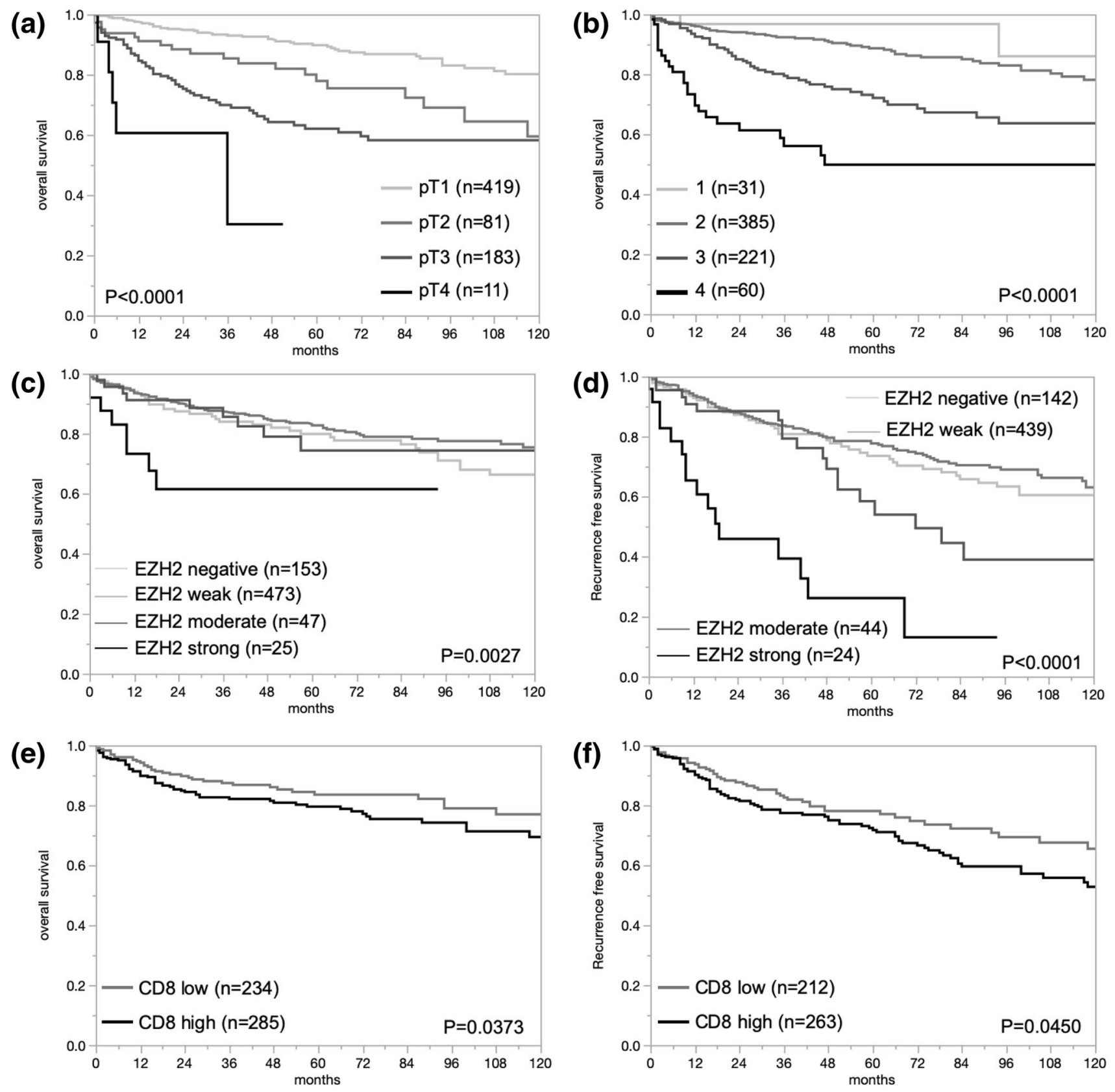

Fig. 2 Comparison to prognosis in renal cell carcinomas (RCC). a pT and overall survival in clear cell RCC (ccRCC), b Fuhrmann grading and overall survival in ccRCC, $\mathbf{c}$ EZH2 immunostaining and overall

survival in ccRCC, d EZH2 and recurrence free survival in ccRCC, e CD8 and overall survival in ccRCC, and $\mathbf{f ~ C D 8}$ and recurrence free survival in ccRCC

we have previously shown that the usage of one tissue core per cancer is sufficient to find relevant associations between molecular alterations and tumor phenotype or patient prognosis [31, 32]. In an extensive analysis of multiple molecular markers in sets of 50-12,000 prostate cancers, we demonstrated the relationship between the number of analyzable tumors and the statistical power of TMA studies [33]. In

a typical TMA analysis with one spot per cancer, about $60-80 \%$ of tumors will be analyzable. Obviously, this fraction can be increased if the number of samples per tumor is increased. However, considering that the analysis of 100 cancers with five spots each will result in 90-100 interpretable cancers, while a TMA made from 500 cancers with one spot each will result in 300-350 interpretable cancers, we 
Table 4 Comparison between the density of CD8+ cells and renal cell cancer subtypes

\begin{tabular}{lcrr}
\hline Entity & \multicolumn{3}{c}{ Density of CD8+ cells $\left(\right.$ cell $\left./ \mathrm{mm}^{2}\right)$} \\
\cline { 2 - 4 } & Analyzable $(n)$ & Mean & \multicolumn{1}{c}{ SD } \\
\hline Renal cell cancers (RCC) & 1163 & 342.3 & 611.7 \\
Clear cell RCC & 770 & 430.4 & 21.5 \\
Papillary RCC & 173 & 189.5 & 45.4 \\
Chromophobe RCC & 60 & 87.5 & 77.1 \\
Clear cell tubulopapillary RCC & 19 & 191.0 & 137.1 \\
Oncocytomas & 85 & 47.2 & 64.8 \\
Other rare types & 56 & 374.1 & 79.8 \\
\hline
\end{tabular}

Table 5 Comparison of the density of CD8+ cells and clinico-pathological features in clear cell renal cell cancers

\begin{tabular}{|c|c|c|c|c|}
\hline \multirow[t]{2}{*}{ Parameter } & \multicolumn{4}{|c|}{ Density of CD8+ cells (cell/ $/ \mathrm{mm}^{2}$ ) } \\
\hline & Analyzable $(n)$ & mean & SD & $p$ value \\
\hline \multicolumn{5}{|l|}{ ISUP } \\
\hline 1 & 212 & 269.7 & 46.2 & \multirow[t]{4}{*}{$<0.0001$} \\
\hline 2 & 255 & 378.8 & 42.2 & \\
\hline 3 & 233 & 596.1 & 44.1 & \\
\hline 4 & 61 & 576.5 & 86.2 & \\
\hline \multicolumn{5}{|l|}{ Fuhrmann } \\
\hline 1 & 41 & 210.2 & 105.1 & \multirow[t]{4}{*}{$<0.0001$} \\
\hline 2 & 420 & 346.2 & 32.8 & \\
\hline 3 & 240 & 564.0 & 43.5 & \\
\hline 4 & 68 & 616.9 & 81.6 & \\
\hline \multicolumn{5}{|l|}{ Thoenes } \\
\hline 1 & 258 & 299.2 & 42.1 & \multirow[t]{3}{*}{$<0.0001$} \\
\hline 2 & 408 & 467.6 & 33.4 & \\
\hline 3 & 103 & 615.4 & 66.6 & \\
\hline \multicolumn{5}{|c|}{ Tumor stage } \\
\hline pT1 & 448 & 374.1 & 31.9 & \multirow[t]{4}{*}{0.0734} \\
\hline pT2 & 80 & 461.1 & 75.6 & \\
\hline pT3 & 225 & 517.5 & 45.1 & \\
\hline pT4 & 12 & 443.6 & 195.2 & \\
\hline \multicolumn{5}{|c|}{ Lymph node metastasis } \\
\hline pN0 & 116 & 432.5 & 54.6 & \multirow[t]{3}{*}{0.3965} \\
\hline pN1 & 7 & 132.5 & 222.4 & \\
\hline pN2 & 17 & 357.4 & 142.7 & \\
\hline \multicolumn{5}{|c|}{ Distant metastasis } \\
\hline pM0 & 94 & 357.7 & 70.1 & \multirow[t]{2}{*}{0.0383} \\
\hline pM1 & 85 & 570.0 & 73.7 & \\
\hline
\end{tabular}

Numbers do not always add up to 770 in the different categories because of missing data

strongly feel that analysis of one tissue core per cancer is preferable over the analysis of multiple cores.

The strong association between high EZH2 protein overexpression and poor patient outcome found in our cohort is well consistent with data from earlier studies. We did not analyze the mechanisms underlying EZH2 overexpression in our tumor cohort, but there is evidence from the literature that NF-kB, MUC1-C, KRAS, MEK-ERK and PI3KAKT signaling might cause significant EZH2 up regulation in human cancers [34-36]. Interestingly, there are reports that infiltration of $\mathrm{CD} 8+$ lymphocytes may be among these factors at least in bladder, prostate and renal cell cancer [37-39]. Associations between high EZH2 levels and poor patient outcome in RCC patients has been described in nine earlier IHC-based reports [14-22]. In addition, an analysis of the RNA expression data of 1992 kidney tumors collected from several databases including The Cancer Genome Atlas (TCGA) suggested that high EZH2 expression might serve as a predictor for early cancer specific death in low and intermediate risk tumors, but not in high risk tumors [20]. All earlier studies had either analyzed clear cell RCC [15, 18-21] or cohorts containing various RCC subtypes [14, 16, $17,22]$. We used overall survival instead of cancer specific survival as an endpoint of our study for two reasons. First, tumor specific data were available only for a small subset of our patients. Second, it is difficult to judge whether such data actually reflect the reason for death in a generally elderly patient cohort.

For the purpose of this study, the CD8+ cytotoxic T-lymphocyte density was quantitated using a digital image analysis algorithm to calculate the number of CD8+ cells per measured square millimeter. The density of CD8+ cells obtained by this approach on our RCC TMA was comparable to the values that we earlier collected for clear cell RCC ( $306 \pm 479$; this study $430 \pm 22)$ and papillary RCC $(141 \pm 149$; this study $190 \pm 45)$ in a study assessing the number of CD8+ cells across a broad range of different tumor entities (manuscript under revision, Cellular Oncology). The association between high density of CD8+ cells and poor patient outcome is consistent with data from two earlier studies, analyzing 221 [40] and 135 [40] RCCs. Overall, these findings describe an unusual role of CD8+ cells in RCC as high numbers of CD8+ cells are strongly linked to favorable prognosis in most other cancer types including advanced urothelial cancer [41], breast cancer [42], pancreatic carcinomas [43], colorectal cancer [44] and others. The link between high density of CD8+ cells and favorable prognosis is so strong in colorectal cancer, that various authors suggest lymphocyte quantification to become a routine procedure in these tumors [26, 45-47]. It has been suggested, that the different clinical impact of CD8+ cells between RCC and colorectal carcinoma may either reflect different tumor tissue organization or relate to tumor type specific other factors of the tumor microenvironment [40].

It is of note that the prognostic role of the density of CD8+ cells in RCC might be depending on the type of previous treatments, as recent work has suggested. George et al. 
Fig. 3 Association of EZH2 immunostaining and the density of CD8+ cells

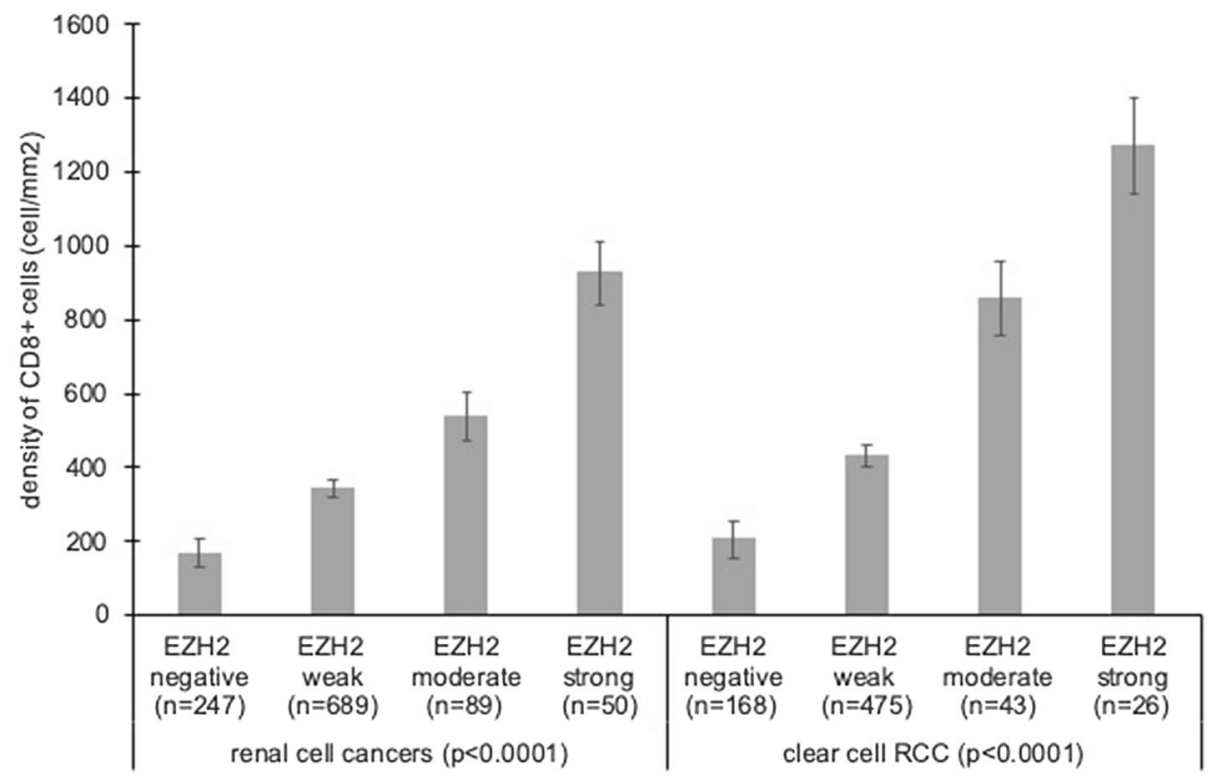

analyzed the density of CD8+ cells in patients with locoregional high-risk RCC who were either treated with Sunitinib or Placebo in the S-TRAC trial and found that increased density of CD8+ cells was associated with longer disease free survival in the group of patients treated with Sunitinib, but not in the group treated with Placebo [48]. These authors suggested that cancer necrosis induced by VEGF/VEGFR inhibition and tumor hypoxia might result in an increased exposure of neoantigens that could be recognized and targeted by CD8+ cells. Necrosis-driven neoantigen exposure is a mechanism that may be unrelated to the type of therapy. However, Yao et al. [49] recently found that the role of CD8 might depend on the type of therapy, as patients with high density of CD8+ cells in metastases from RCCs only showed prolonged overall survival when sunitinib, but not sorafenib was the prior treatment.

The strong link between high EZH2 expression levels and a high density of CD8+ cells found in our study is consistent with a functionally relevant interaction of EZH2 protein expression and the immune response to tumor cells. This notion is supported by recent data of Zingg et al. [23] demonstrating that intratumoral T-cell accumulation-among other factors-can result in increased EZH2 expression in melanoma cells, which in return leads to a loss of immunogenicity and antigen presentation in EZH2 overexpressing tumor cells. EZH2 inactivation in this scenario caused a regain of immunogenicity. As similar findings could not be obtained in lung and colon cancer cells, the authors concluded that this mechanism might not be universally applicable but dependent on the tumor type [23]. Based on these observations, one might speculate that lymphocytic infiltration might cause a particular strong EZH2 overexpression in $\mathrm{RCC}$ and the resulting immune evasion causes the poor patient outcome in kidney cancers with high CD8+ cell density. A RCC specificity of such a mechanism could explain the unique association between high density of CD8+ cells and unfavorable disease outcome in RCC which markedly differs from findings in most other cancer types (i.e., urothelial cancer [41], breast cancer [42], pancreatic carcinomas [43], colorectal cancer [44] and others [50]).

In summary, our data show that high EZH2 protein expression is linked to poor prognosis in RCC. The tight relationship of $\mathrm{EZH} 2$ expression levels and the density of $\mathrm{CD} 8+$ cells in $\mathrm{RCC}$ is consistent with recent functional data by Zingg et al. [23] and might explain the unusual finding of a link between high lymphocyte content and poor prognosis in RCC patients.

Acknowledgements Open Access funding provided by Projekt DEAL. We are grateful to Melanie Witt, Sünje Seekamp, Inge Brandt, and Maren Eisenberg for excellent technical assistance.

Author contributions All authors contributed to the study conception and design. Material preparation, data collection and analysis were performed by TE, LS, CF, TM, NCB, MK, CH-M, KM, TC, SW, RD, MF, SR, and FB. The first draft of the manuscript was written by TE, MK, RS and GS and all authors commented on previous versions of the manuscript. All authors read and approved the final manuscript.

\section{Compliance with ethical standards}

Conflict of interest The authors declare that they have no conflict of interest.

Research involving human participants and/or animals The usage of archived diagnostic left-over tissues for manufacturing of TMAs and their analysis for research purposes as well as patient data analysis has been approved by local laws (HmbKHG, §12,1) and by the local ethics 
committee (Ethics commission Hamburg, WF-049/09). All work has been carried out in compliance with the Helsinki Declaration.

Open Access This article is licensed under a Creative Commons Attribution 4.0 International License, which permits use, sharing, adaptation, distribution and reproduction in any medium or format, as long as you give appropriate credit to the original author(s) and the source, provide a link to the Creative Commons licence, and indicate if changes were made. The images or other third party material in this article are included in the article's Creative Commons licence, unless indicated otherwise in a credit line to the material. If material is not included in the article's Creative Commons licence and your intended use is not permitted by statutory regulation or exceeds the permitted use, you will need to obtain permission directly from the copyright holder. To view a copy of this licence, visit http://creativecommons.org/licenses/by/4.0/.

\section{References}

1. Jonasch E, Gao J, Rathmell WK (2014) Renal cell carcinoma. BMJ 349:g4797

2. Motzer RJ, Tannir NM, McDermott DF, Aren Frontera O, Melichar B, Choueiri TK et al (2018) Nivolumab plus Ipilimumab versus Sunitinib in advanced renal-cell carcinoma. N Engl J Med 378:1277-1290

3. Choueiri TK, Halabi S, Sanford BL, Hahn O, Michaelson MD, Walsh MK et al (2017) Cabozantinib versus Sunitinib as initial targeted therapy for patients with metastatic renal cell carcinoma of poor or intermediate risk: the alliance A031203 CABOSUN trial. J Clin Oncol 35:591-597

4. Addeo A, Banna GL, Metro G, Di Maio M (2019) Chemotherapy in combination with immune checkpoint inhibitors for the firstline treatment of patients with advanced non-small cell lung cancer: a systematic review and literature-based meta-analysis. Front Oncol 9:264

5. Katz H, Biglow L, Alsharedi M (2019) Immune checkpoint inhibitors in locally advanced, unresectable, and metastatic upper gastrointestinal malignancies. J Gastrointest Cancer. https://doi. org/10.1007/s12029-019-00243-8

6. Khair DO, Bax HJ, Mele S, Crescioli S, Pellizzari G, Khiabany A et al (2019) Combining immune checkpoint inhibitors: established and emerging targets and strategies to improve outcomes in melanoma. Front Immunol 10:453

7. Ljungberg B, Albiges L, Abu-Ghanem Y, Bensalah K, Dabestani S, Fernandez-Pello S et al (2019) European association of urology guidelines on renal cell carcinoma: the 2019 update. Eur Urol 75:799-810

8. Rini BI, Plimack ER, Stus V, Gafanov R, Hawkins R, Nosov D et al (2019) Pembrolizumab plus Axitinib versus Sunitinib for advanced renal-cell carcinoma. N Engl J Med 380:1116-1127

9. Motzer RJ, Penkov K, Haanen J, Rini B, Albiges L, Campbell MT et al (2019) Avelumab plus Axitinib versus Sunitinib for advanced renal-cell carcinoma. N Engl J Med 380:1103-1115

10. Sauvageau M, Sauvageau G (2010) Polycomb group proteins: multi-faceted regulators of somatic stem cells and cancer. Cell Stem Cell 7:299-313

11. Cao Q, Yu J, Dhanasekaran SM, Kim JH, Mani RS, Tomlins SA et al (2008) Repression of E-cadherin by the polycomb group protein EZH2 in cancer. Oncogene 27:7274-7284

12. Kotake Y, Cao R, Viatour P, Sage J, Zhang Y, Xiong Y (2007) pRB family proteins are required for $\mathrm{H} 3 \mathrm{~K} 27$ trimethylation and polycomb repression complexes binding to and silencing p16INK4alpha tumor suppressor gene. Genes Dev 21:49-54

13. Kim E, Kim M, Woo DH, Shin Y, Shin J, Chang N et al (2013) Phosphorylation of EZH2 activates STAT3 signaling via STAT3 methylation and promotes tumorigenicity of glioblastoma stemlike cells. Cancer Cell 23:839-852

14. Liu L, Xu Z, Zhong L, Wang H, Jiang S, Long Q et al (2013) Prognostic value of EZH2 expression and activity in renal cell carcinoma: a prospective study. PLoS ONE 8:e81484

15. Sun C, Zhao C, Li S, Wang J, Zhou Q, Sun J et al (2018) EZH2 expression is increased in BAP1-mutant renal clear cell carcinoma and is related to poor prognosis. J Cancer 9:3787-3796

16. Wagener N, Macher-Goeppinger S, Pritsch M, Husing J, HoppeSeyler K, Schirmacher P et al (2010) Enhancer of zeste homolog 2 (EZH2) expression is an independent prognostic factor in renal cell carcinoma. BMC Cancer 10:524

17. Wang Y, Chen Y, Geng H, Qi C, Liu Y, Yue D (2015) Overexpression of $\mathrm{YB} 1$ and EZH2 are associated with cancer metastasis and poor prognosis in renal cell carcinomas. Tumour Biol 36:7159-7166

18. Xu B, Abourbih S, Sircar K, Kassouf W, Mansure JJ, Aprikian A et al (2013) Enhancer of zeste homolog 2 expression is associated with metastasis and adverse clinical outcome in clear cell renal cell carcinoma: a comparative study and review of the literature. Arch Pathol Lab Med 137:1326-1336

19. Xu ZQ, Zhang L, Gao BS, Wan YG, Zhang XH, Chen B et al (2015) EZH2 promotes tumor progression by increasing VEGF expression in clear cell renal cell carcinoma. Clin Transl Oncol 17:41-49

20. Ho TH, Kapur P, Eckel-Passow JE, Christie A, Joseph RW, Serie DJ et al (2017) Multicenter validation of enhancer of zeste homolog 2 expression as an independent prognostic marker in localized clear cell renal cell carcinoma. J Clin Oncol 35:3706-3713

21. Lee HW, Choe M (2012) Expression of EZH2 in renal cell carcinoma as a novel prognostic marker. Pathol Int 62:735-741

22. Sakurai T, Bilim VN, Ugolkov AV, Yuuki K, Tsukigi M, Motoyama $\mathrm{T}$ et al (2012) The enhancer of zeste homolog 2 (EZH2), a potential therapeutic target, is regulated by miR-101 in renal cancer cells. Biochem Biophys Res Commun 422:607-614

23. Zingg D, Arenas-Ramirez N, Sahin D, Rosalia RA, Antunes AT, Haeusel J et al (2017) The histone methyltransferase Ezh2 controls mechanisms of adaptive resistance to tumor immunotherapy. Cell Rep 20:854-867

24. Eichelberg C, Minner S, Isbarn H, Burandt E, Terracciano L, Moch H et al (2013) Prognostic value of alpha-methyl CoA racemase (AMACR) expression in renal cell carcinoma. World J Urol 31:847-853

25. Kononen J, Bubendorf L, Kallioniemi A, Barlund M, Schraml P, Leighton $\mathrm{S}$ et al (1998) Tissue microarrays for high-throughput molecular profiling of tumor specimens. Nat Med 4:844-847

26. Galon J, Costes A, Sanchez-Cabo F, Kirilovsky A, Mlecnik B, Lagorce-Pages $\mathrm{C}$ et al (2006) Type, density, and location of immune cells within human colorectal tumors predict clinical outcome. Science 313:1960-1964

27. Hinz S, Weikert S, Magheli A, Hoffmann M, Engers R, Miller $\mathrm{K}$ et al (2009) Expression profile of the polycomb group protein enhancer of zeste homologue 2 and its prognostic relevance in renal cell carcinoma. J Urol 182:2920-2925

28. Liu L, Xu Z, Zhong L, Wang H, Jiang S, Long Q et al (2016) Enhancer of zeste homolog 2 (EZH2) promotes tumour cell migration and invasion via epigenetic repression of E-cadherin in renal cell carcinoma. BJU Int 117:351-362

29. Hirata H, Hinoda Y, Shahryari V, Deng G, Nakajima K, Tabatabai ZL et al (2015) Long noncoding RNA MALAT1 promotes 
aggressive renal cell carcinoma through Ezh2 and interacts with miR-205. Cancer Res 75:1322-1331

30. Nocito A, Bubendorf L, Tinner EM, Suess K, Wagner U, Forster $T$ et al (2001) Microarrays of bladder cancer tissue are highly representative of proliferation index and histological grade. J Pathol 194:349-357

31. Schroeder C, Navid-Hill E, Meiners J, Hube-Magg C, Kluth M, Makrypidi-Fraune G et al (2019) Nuclear ELAC2 overexpression is associated with increased hazard for relapse after radical prostatectomy. Oncotarget 10:4973-4986

32. Kluth M, Runte F, Barow P, Omari J, Abdelaziz ZM, Paustian L et al (2015) Concurrent deletion of 16q23 and PTEN is an independent prognostic feature in prostate cancer. Int $\mathrm{J}$ Cancer 137:2354-2363

33. Burdelski C, Matuszewska A, Kluth M, Koop C, Grupp K, Steurer S et al (2014) Qualitative and quantitative requirements for assessing prognostic markers in prostate cancer. Microarrays (Basel) 3:137-158

34. Fujikawa D, Nakagawa S, Hori M, Kurokawa N, Soejima A, Nakano K et al (2016) Polycomb-dependent epigenetic landscape in adult T-cell leukemia. Blood 127:1790-1802

35. Rajabi H, Hiraki M, Tagde A, Alam M, Bouillez A, Christensen CL et al (2017) MUC1-C activates EZH2 expression and function in human cancer cells. Sci Rep 7:7481

36. Riquelme E, Behrens C, Lin HY, Simon G, Papadimitrakopoulou V, Izzo J et al (2016) Modulation of EZH2 expression by MEKERK or PI3K-AKT signaling in lung cancer is dictated by different KRAS oncogene mutations. Cancer Res 76:675-685

37. Komohara Y, Harada M, Arima Y, Suekane S, Noguchi M, Yamada A et al (2007) Identification of target antigens in specific immunotherapy for renal cell carcinoma. J Urol 177:1157-1162

38. Komohara Y, Harada M, Arima Y, Suekane S, Noguchi M, Yamada A et al (2006) Anti-cancer vaccine candidates in specific immunotherapy for bladder carcinoma. Int J Oncol 29:1555-1560

39. Minami T, Minami T, Shimizu N, Yamamoto Y, De Velasco MA, Nozawa $M$ et al (2015) New polycomb group protein enhancer of zeste homolog (EZH) 2-derived peptide with the potential to induce cancer-reactive cytotoxic $\mathrm{T}$ lymphocytes in prostate cancer patients with HLA-A3 supertype alleles. Int Immunopharmacol 26:133-138

40. Nakano O, Sato M, Naito Y, Suzuki K, Orikasa S, Aizawa M et al (2001) Proliferative activity of intratumoral CD8(+) T-lymphocytes as a prognostic factor in human renal cell carcinoma: clinicopathologic demonstration of antitumor immunity. Cancer Res 61:5132-5136

41. Sharma P, Shen Y, Wen S, Yamada S, Jungbluth AA, Gnjatic S et al (2007) CD8 tumor-infiltrating lymphocytes are predictive of survival in muscle-invasive urothelial carcinoma. Proc Natl Acad Sci USA 104:3967-3972

42. Mahmoud SM, Paish EC, Powe DG, Macmillan RD, Grainge MJ, Lee AH et al (2011) Tumor-infiltrating CD8+ lymphocytes predict clinical outcome in breast cancer. J Clin Oncol 29:1949-1955

43. Fukunaga A, Miyamoto M, Cho Y, Murakami S, Kawarada Y, Oshikiri T et al (2004) CD8+ tumor-infiltrating lymphocytes together with CD4+ tumor-infiltrating lymphocytes and dendritic cells improve the prognosis of patients with pancreatic adenocarcinoma. Pancreas 28:e26-e31

44. Naito Y, Saito K, Shiiba K, Ohuchi A, Saigenji K, Nagura H et al (1998) CD8+ T cells infiltrated within cancer cell nests as a prognostic factor in human colorectal cancer. Cancer Res 58:3491-3494

45. Pages F, Galon J, Dieu-Nosjean MC, Tartour E, Sautes-Fridman C, Fridman WH (2010) Immune infiltration in human tumors: a prognostic factor that should not be ignored. Oncogene 29:1093-1102

46. Bindea G, Mlecnik B, Fridman WH, Galon J (2011) The prognostic impact of anti-cancer immune response: a novel classification of cancer patients. Semin Immunopathol 33:335-340

47. Pages F, Mlecnik B, Marliot F, Bindea G, Ou FS, Bifulco C et al (2018) International validation of the consensus immunoscore for the classification of colon cancer: a prognostic and accuracy study. Lancet 391:2128-2139

48. George DJ, Martini JF, Staehler M, Motzer RJ, Magheli A, Escudier B et al (2018) Immune biomarkers predictive for disease-free survival with adjuvant Sunitinib in high-risk locoregional renal cell carcinoma: from randomized phase III S-TRAC study. Clin Cancer Res 24:1554-1561

49. Yao J, Xi W, Zhu Y, Wang H, Hu X, Guo J (2018) Checkpoint molecule PD-1-assisted CD8(+) T lymphocyte count in tumor microenvironment predicts overall survival of patients with metastatic renal cell carcinoma treated with tyrosine kinase inhibitors. Cancer Manag Res 10:3419-3431

50. Fridman WH, Zitvogel L, Sautes-Fridman C, Kroemer G (2017) The immune contexture in cancer prognosis and treatment. Nat Rev Clin Oncol 14:717-734

Publisher's Note Springer Nature remains neutral with regard to jurisdictional claims in published maps and institutional affiliations. 